operative procedure, the examination, roentgenologically, of the chest, pelvis, spine, humeri and femora in all cases of suspected cancer of the breast. It may be objected that this method is expensive. That is true; but expense matters little when useless surgery is prevented. It may also be urged that a radical operation relieves suffering and prolongs life even in advanced cases; but actually how much longer is life preserved and how much suffering is saved than would be the case under skillful medical treatment? As far as I am aware, this is an original method,- - as I have not seen any advocation of it in the literature,-and is presented with the hope that it will help to safeguard the radical operation for carcinoma of the breast, which is fast coming into ill-repute with the people.

\section{OCliniral Papartment.}

\section{AURICULAR STANDSTILL: AN UNUSUAL EFFEC'T OF DIGITALIS ON THE HEART, WITH ESPECIAL REFERENCE TO THE ELEC'TROCARDIOGRAM.}

By Paul D. White, M.D., Boston.

[From the Medical Service of the Massachusetts General Hospital, Boston.]

Diarralis may affect the human heart and electrocardiogram in a variety of ways. A total bradycardia may occur in which the pacemaker in the sinoauricular node is depressed and slowed. Heart-block may be produced, varying from delayed A-V conduction to complete block, the grade depending on the amount of digitalis given and on the condition of the A-V conduction system. Ventricular escape may occur, due to a decrease of sinoauricular rate below the rate of the atrioventricular nodal pacemaker or to an increase of the lower nodal rate over that of the upper node. Aberrant ventricular complexes in the electrocardiogram may follow digitalis administration. In cases of auricular fibrillation large amounts of digitalis may produce a bigeminy due to the occurrence of ectopic ventricular contractions at every second beat. The shape of the $T$ wave of the electrocardiogram is definitely altered by digitaiis; if, for example, the $T$ is upright in Lead II, it becomes depressed and finally inverted as the result of the administration of digitalis.

There is one further effect which may oceur in diseased hearts after digitalis, which has not hitherto been described as such, so far as I am aware. That is the removal by digitalis of all evidence of auricular activity from electrocardiogram and from the jugular pulse tracing. There is no evidence that the auricle is contract- ing at all. Against the possibility of an isoclectric $P$ in Lead II is the absence of $P$ in Leads $I$ and III also, and the absence of $a$ in the jugular pulse. Auricular fibrillation may be excluded by the entire absence of fibrillation oscillations of the galvanometric string and the perfectly regular ventricular rate. The atrioventricular node is probably giving rise to the ventricular complexes, because their shape is that of the normal complexes of supraventricular origin and they occur regularly. No deflections appear suggesting that the atrioventricular node is also giving rise to auricular activity. In other words, there appears to be auricular standstill. This condition has been produced experimentally in the cat $^{2}$ by depression of the sinoauricular node by cold and depression of the junction of auricle and atrioventricular node by asphyxia.

'Three cases have been found at the Massachusetts General Hospital in which this digitalis effect has been seen. All three showed definite evidence of auricular action in electrocardiogram and jugular pulse tracings after the effects of the digitalis intoxication had worn off; in all three the A-V conduction time showed some delay during the recovery from the digitalis. In none of the three, at the time of the disappearance of auricular activity, was there any evidence of auricular fibrillation, ventricular escape or complete atrioventricular rhythm.

Lewis ${ }^{1}$ has reported one case of unusual bradycardia in which there was no trace of auricular aetivity in electrocardiogram or jugular tracing. No note was made as to digitalis administration in this case.

Electrocardiograms from the three cases seen at the Massachusetts General Hospital, without evidence of auricular actiyity, are shown in Figs. 1,3 and 4. A short account of these cases follows :

CAse 1. Man of 80 years, with arteriosclerosis and myocardial weakness. In June, 1914, a polygram showed a long $a-c$ interval in the jugular pulse. On March 11, 1915, after about 2.5 grams of digitalis in the course of three weeks, electrocardiograms showed no $P$ wave but did show a definite digitalis effect on the $T$ wave, consisting of inversion of this deflection (Fig. 'Ia). Diastole was smooth, without evidence of auricular fibrillation. The ventricles were beating regularly. Fig. 2a shows a polygram taken this same day, also without evidence of auricular action. At other times this patient has shown ventricular escape with simultaneous auricular and ventricular contractions: when auricle and ventricle beat simultaneously, very large waves occurred in the jugular pulse, representing $\mathrm{a}$ and $\mathrm{c}$ or $\mathrm{a}$ and $\mathrm{v}$ together. (Fig. 2c.) Digitalis was stopped, and on March 21, 1915, a polygram showed normal rhythm, with a long $a-c$ interval, and a pulse rate of 40 . (Fig. 2b.) An electrocardiogram taken April 8, 1915, shows the normal rhythm with the $P$ wave present in every lead, and the $T$ wave returned to normal (Fig. 1b).

CASE 2. Man of 69 years, with cardiosclerosis and 


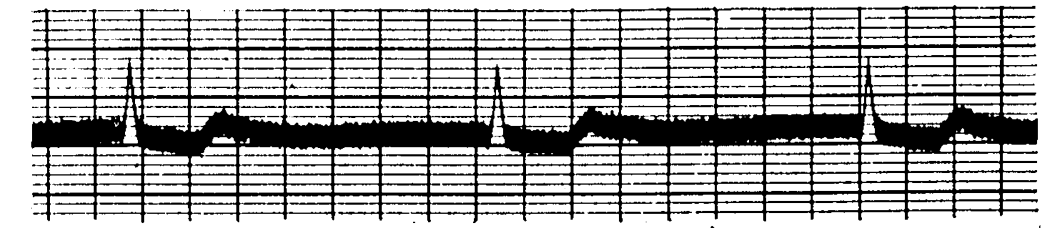

I.

$a$.

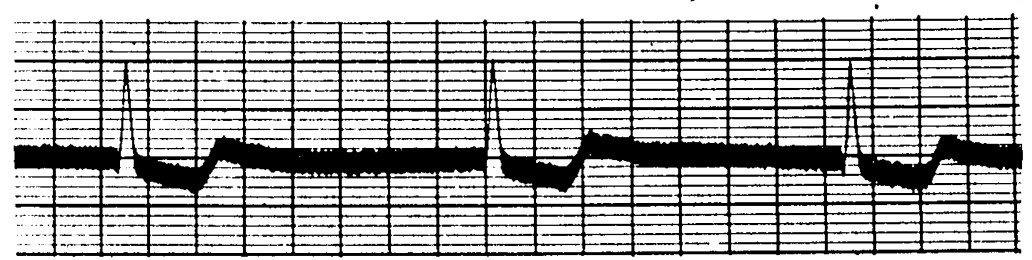

II.
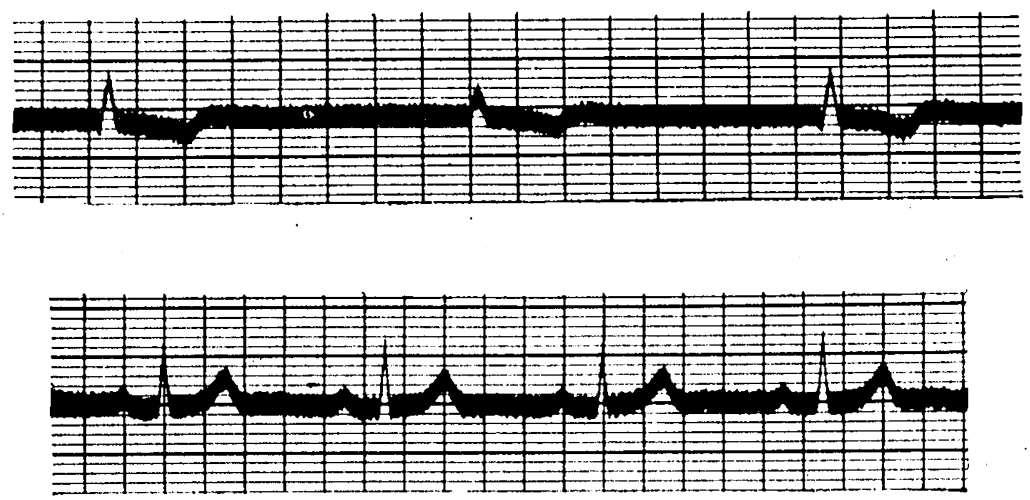

I.

II.

b.
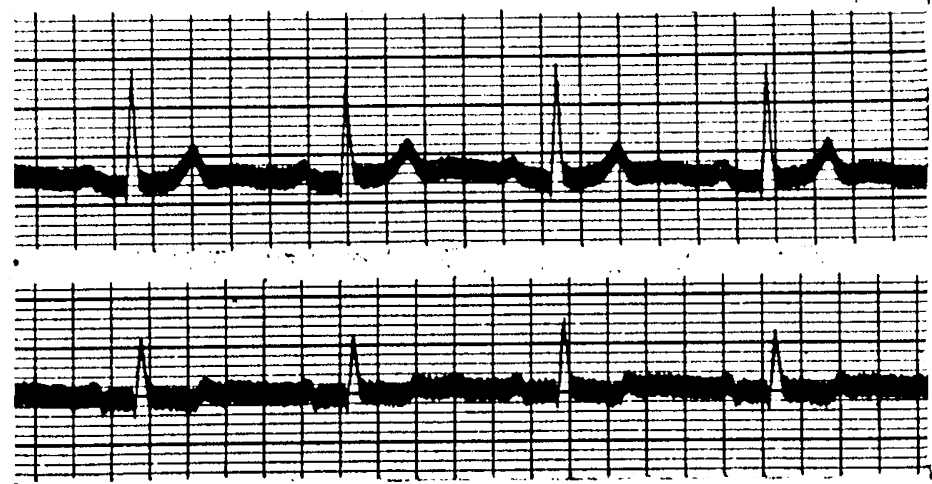

III.

Fili. 1.

In Figs. 1,8 and 4 abscissa $=0.2$ second ; ordinate $=10^{-A}$ volt

a. The three electrocurdiogruphic leads of G. H. A. showing digitalis effects-absence of auricular

b. The defertions und invert $T$. Rate $=30$. March 11, 1015

G. II. A. showing normal rhythm with $P$ present in every lead. $P \cdot R$ interval

is slightly prolonged. Rate $=55$. April 9,1915 .

cardiac weakness. On Nov. 28, 1914, an electrocardiogram showed normal rhythm and defective conduction in the right bundle branch. After 1.7 grams of digitalis an electrocardiogram, taken Dec. 15, 1914, showed absence of auricular activity (Fig. 3a). A tropin sulphate, gr, $1 / 50$ subcutaneously, failed to change the electrocardiogram except for slight increase in rate. Digitalis was stopped and on Dec. 29 an electrocardiogram showed normal rhythm with $P$ wave present.

CASE 3. Man of 37 years, with atrioventricular rhythm following auricular flutter, and already described in detail in a previous paper. " On two occasions, a month or more apart, the auricular deflections were made to disappear from all three leads of the electrocardiogram by courses of digtalis (2.0 grams in a week), as shown in one instance in Fig. 4a (Feb. 23, 1915). There was no evidence of fibrillation. He had shown a characteristic fibrillation record on a previous occasion during the transition from auricular flutter to the atrioventricular rhythm. On still a third occasion, after digitalis, a large number of the ventricular complexes were uliattended by auricular deflections; those that were accompanied by them showed a marked delay in backward conduction across the auriculo-nodal junction (long $R-P$ interval). In this case the sinoauricular node was not functioning and digitalis apparently blocked off the auricle from the atrioventricular pacemaker. An electrocardiogram, showing the return of the auricular deflections in the atrioventricular rhythm, is given in Fig. 4b. 


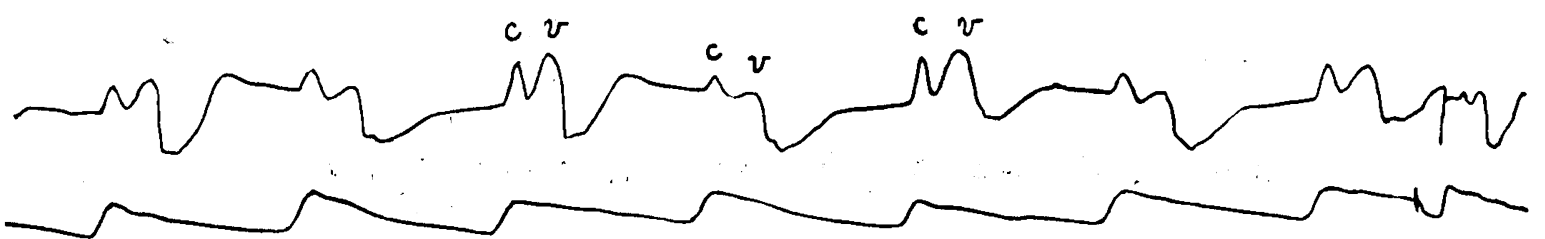

7).
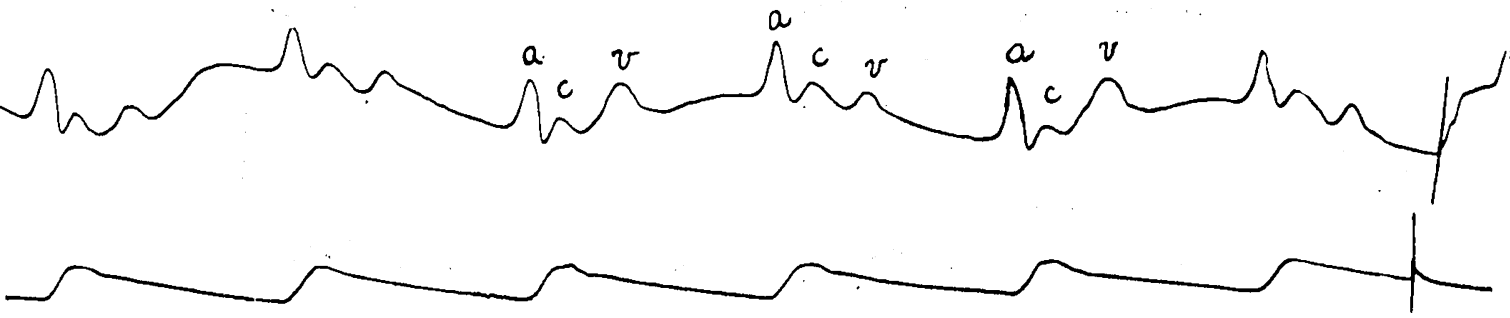

c.

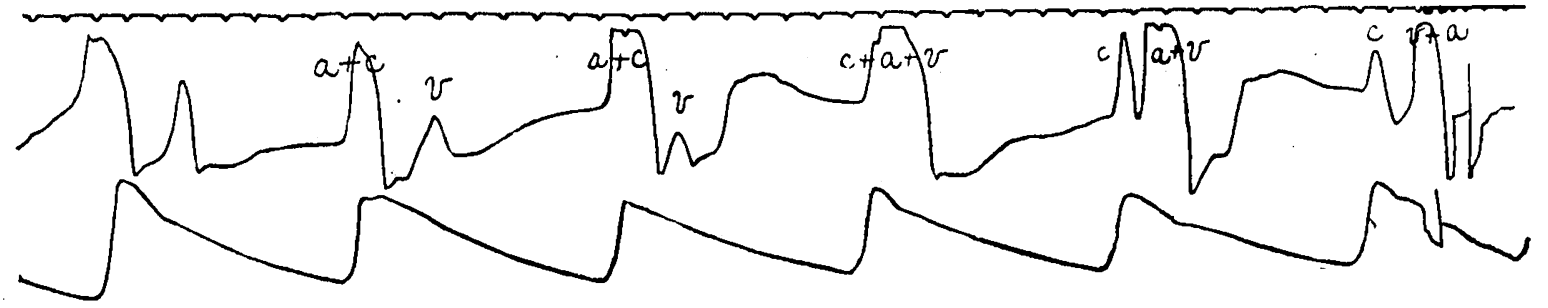

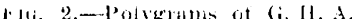

a. Taken March 11, 1915, showing no a wave in the jugular pulse. Time interval $=0.2$ second.
b. Taken March 21, 1015, showing $a$ waves occurring regularly with slighty prolonged a.c intervals.

$b$. Taken March 21, 1015, showing a waves occurring legularly with slightly prolonged $a \cdot c$ intervals.
$c$. Taken March 23, 1015 , showing ventricular escape. The $a$ falls smetimes with the $c$ wave and sometimes with the $v$ wave. Confirmel by electrocartiogram.

a.

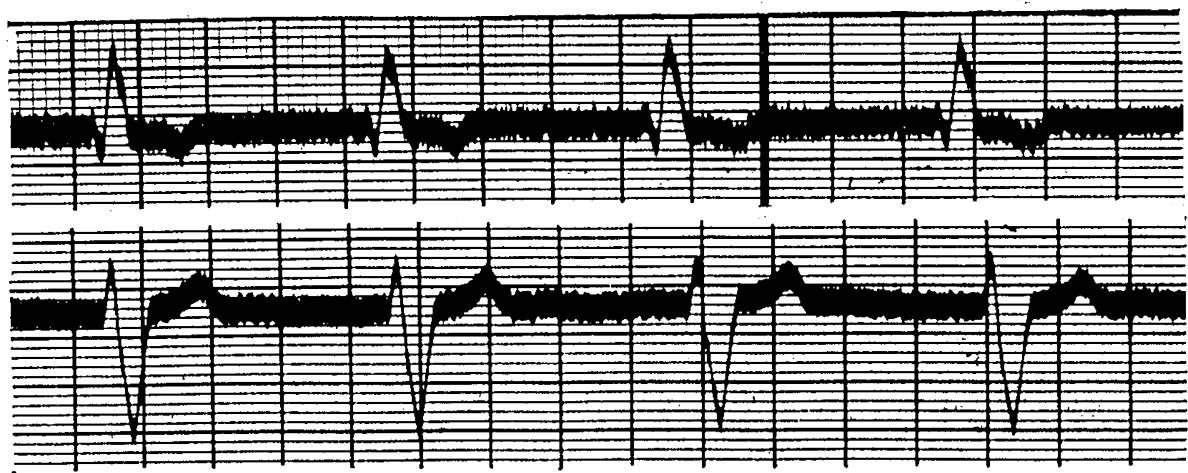

I.

II.

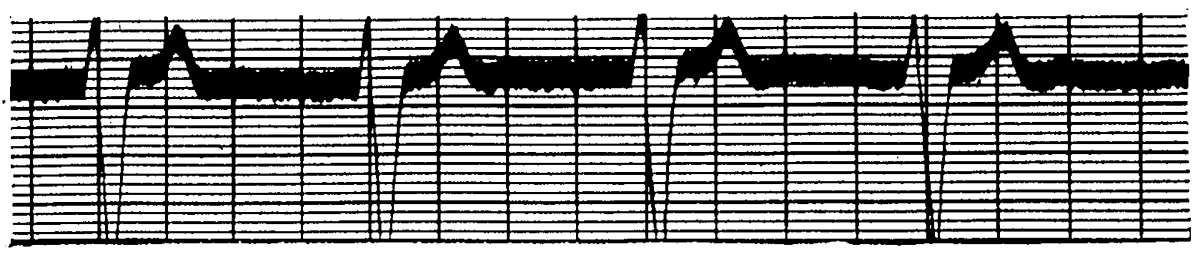

III.

$b$.

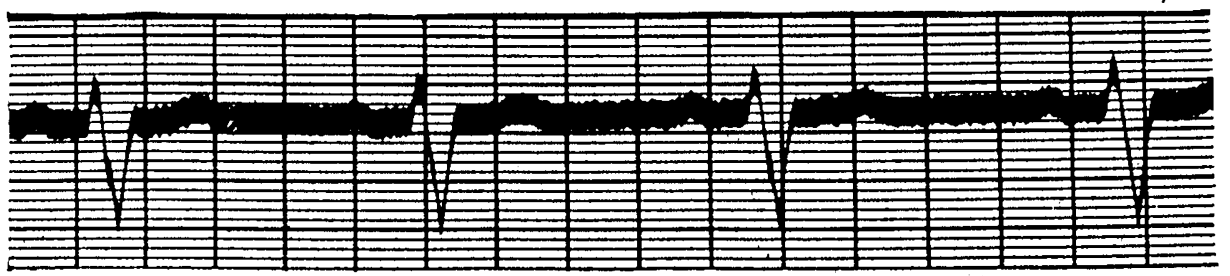

II.

FIG. 3.

a. The three electrocardiographic leads of W. J. B. Dec. 15, 1814, with no evidence of $P$ in any lead. Rate $=73$.

$b$. Lead II of electrocardiogram of W. J. B. Dec. 28,1914 , showing $P$ waves. Rate $=08$. 
a.

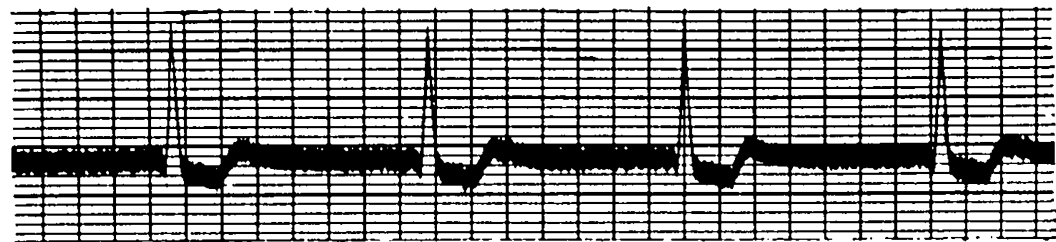

I.

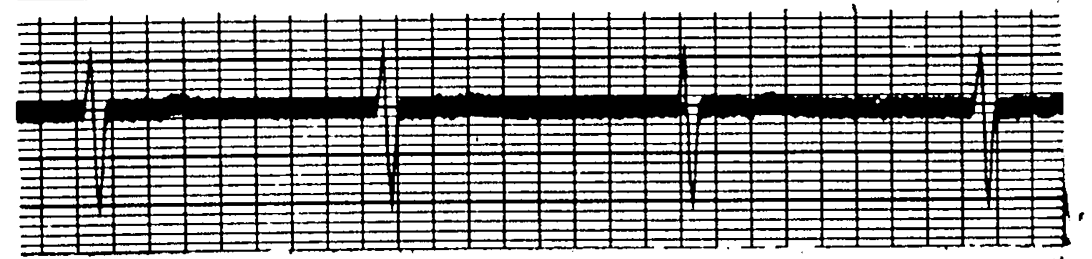

II.

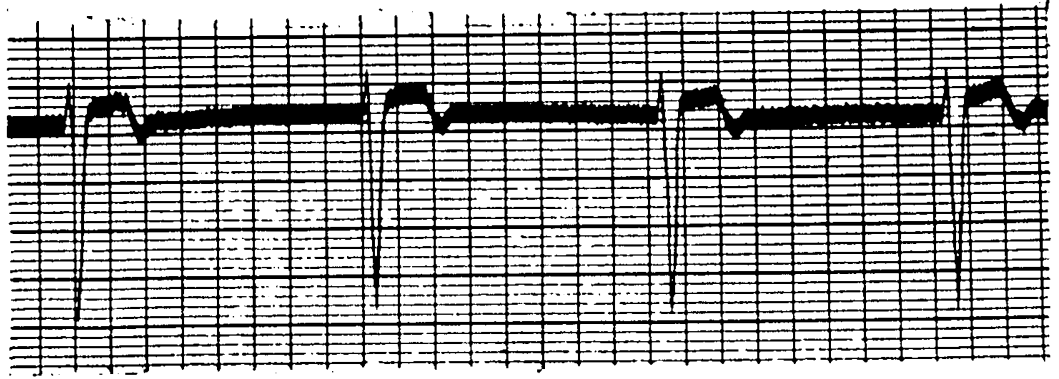

III.

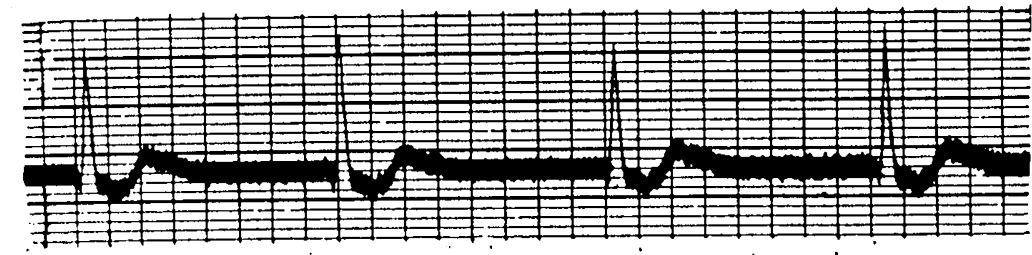

I.

b.
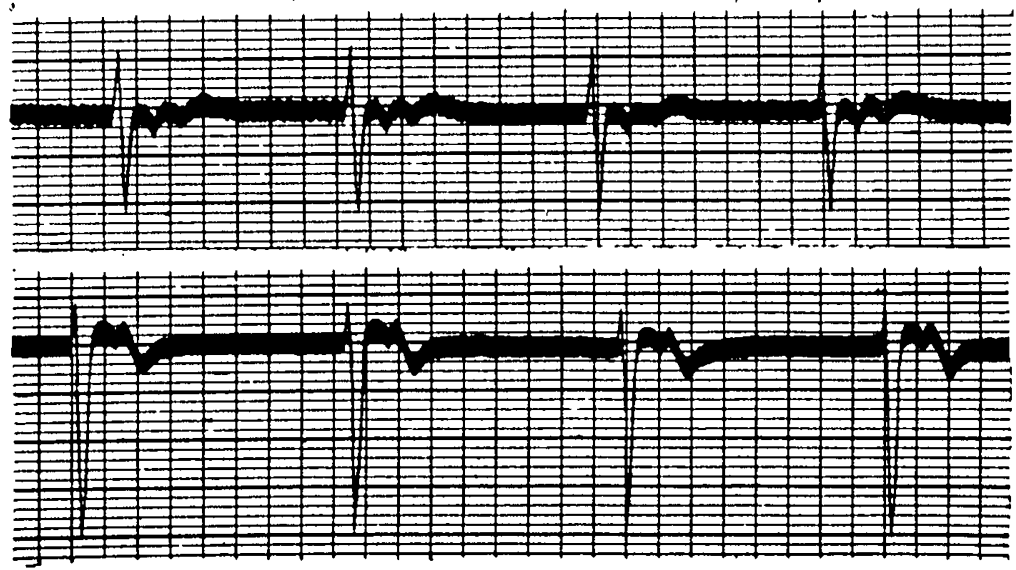

Fia. 4.

a. The three electrocardiographlc leads of W.S., showing no $P$ wave, Feb. 23, 1915.

b. Electrocardiogram of W. S., showing atrioventricular rhythm with inverted $P$. lollow. ing the ventricular complex. Rate $=\mathbf{4 2}$.

SUM MARY.

REPERENCES.

Three cases of heart disease are described in 'Lewis, T.: Exceptional Types of Slow Heart Action, Quart. which electrocardiographic evidence of auricular activity was abolished by digitalis. As soon as the effects of the digitalis had worn off, the auricular deflections reappeared. This is a rare result of digitalis administration. our. Med., 1918, Vol. vi, p. 221.

Lewis, T., White, P. D., and Meakins, J.: The Susceptible Region in A-V Conduction, Heart, 1814, Vol. v, p. 289.

- White, P. D.: A Study of Atrioventricular Rhythm Following Auricular Flutter, Arch. Int. Med., 1915, Vol. xvi, p. 517. 